\title{
Renata Zubrzycka
}

University of Maria Curie-Skłodowska in Lublin, Poland

\section{Coping with stress by mothers of children and adolescents with cystic fibrosis}

The author declares no financial disclosure

\begin{abstract}
Introduction: Studies of coping with stress of parents of children with cystic fibrosis (CF) are relatively rare and their results are inconsistent. The aim of the work was to determine the strategies of coping with stress of Polish mothers of children and adolescents with CF.

Material and methods: The research was conducted in the group of 89 Polish mothers of children with CF (0-18) and used the Brief COPE by Carver in the Polish adaptation by Juczyński and Ogińska-Bulik (2009). The data were compared with the normative results obtained from Polish adults.

Results: The strategies of coping most often used by mothers of children with CF are as follows: active coping, planning and acceptance. A comparison of mean results obtained in the research group and mean results of adults in Polish population revealed that mothers of ill children significantly more often use: active coping, planning, positive reframing, acceptance, religion, seeking of instrumental support and venting. They less often use sense of humour and take psychoactive substance. Use of problem-oriented strategies dominated over use of coping strategies focusing on emotions.

Conclusion: Social support provided to mothers of children with CF should be oriented on strengthening cognitive strategies of coping with stress.
\end{abstract}

Key words: cystic fibrosis, coping with stress, mothers, children, adolescents

Adv Respir Med. 2018; 86: 86-91

\section{Introduction}

In spite of the advancement of medical sciences, cystic fibrosis (CF) remains incurable. It is related to a number of biopsychosocial burdens, both in individual and social contexts [1].

Parents of children and adolescents with CF may experience multiple problems with psychosocial adjustment due to the burdens caused by the disease. Many studies have confirmed that depressive symptoms and anxiety are likely to occur in parents of children with CF [2-4], although the others have shown that caregivers present good psychological adjustment [5-8].
Several concepts of stress have been developed so far. They include transactional model of stress and coping of Lazarus and Folkman [9], Hobfoll's Conservation of Resources Model [10] and Antonovsky's salute-genetic health paradigm [11]. In the present work, Lazarus' and Folkman's concept has been used as a theoretical basis as it deals with stress situations in the processual and transactional contexts. The authors have defined coping as ' constantly changing efforts that include cognitive processes and types of behaviour taken to meet the internal and/or external requirements, which are perceived as overwhelming or exceeding the individual's capabilities'[after: 12, p. 5].

Address for correspondence: Renata Zubrzycka, University of Maria Curie-Skłodowska in Lublin, e-mail: r.zubrzycka@poczta.umcs.lublin.pl

DOI: 10.5603/ARM.2018.0011

Received: 15.12.2017

Copyright (C) 2018 PTChP

ISSN 2451-4934 
Studies of coping with stress of parents of children with CF are relatively rare [13-16]. Reviewing the literature on the process of parental coping with CF, Sheehan, Hiscock et al. [16] discussed two types of coping strategies: passive (e.g. distraction, wishful thinking) and active (e.g. seeking information and support). Coping with stress was also one of the variables studied in Wong, Heriot's exploration [15] conducted on a 34-person group of Australian parents of children with CF, aged 5-12. The variables were measured with the Brief COPE questionnaire [17]. The results of the study showed that the parents of children with CF most often use positive coping strategies, such as acceptance, active coping, planning and seeking for emotional support. The least frequent strategies include the following: using psychoactive substances, behavioural disengagement, denial and religion. Nearly half of the studied parents (42\%) used self-blame strategy, which, as it has been confirmed, is correlated with anxiety, depression in parents, higher impact of the disease on their emotional sphere, and worse psychological state of the child. The interdependence of the avoidance strategies used by parents and behavioural problems in children were confirmed by another Australian study [16].

The proactive strategy of optimistic acceptance in parental coping was predominant in a Czech analysis [18], in which 41 adults with $\mathrm{CF}$ (the average age was 24.41 years) and 63 parents were studied. The explorations were conducted with the use of the Cystic Fibrosis Coping Scale measuring four ways of coping: optimistic acceptance, feeling of hopelessness, denial, and avoidance.

One of the most recently published investigations on the variable of parental coping was conducted in Leuven, Belgium [13]. Thirty eight parents (20 mothers and 18 fathers) of children with CF diagnosed over the last 5 years took part in the studies. The research aimed to investigate the association between coping style (the Utrecht Coping List - UCL) and severity of the disease and time since diagnosis. It turned out that the parents of children with CF more often opt for one of the active coping strategies, i.e. seeking for social support compared to the normative group. The passive strategies, such as 'palliative reaction pattern' based on self-distraction and 'comforting cognitions' were used relatively more often as well. In this study, coping styles were not correlated with the time since diagnosis, or the severity of the disease.
Even though most investigations have focused on mothers of children with CF [19, 20], the number of studies taking into account both parents is increasing $[21,16]$. However, it has not been unequivocally decided whether gender impacts the choice of coping skills. The Kornas-Biela's study [21] reported no significant differences in coping strategies chosen by male and female parents. Recently conducted analyses have showed that mothers more often than fathers seek for social support [13], whereas fathers more often opt for avoidance and self-distraction.

The research aimed at analysing coping strategies of mothers of children and adolescents with $\mathrm{CF}$ and comparing them with the normative results obtained from Polish adults [22].

\section{Material and methods}

\section{Participants and recruitment}

The families were recruited during local and nationwide annual training sessions organised for parents and caregivers by the Polish Cystic Fibrosis Society, established in Rabka Zdrój. The research project was presented to the parents and then 180 sets of questionnaires (with a return envelope and paid postage fees) were given to those showing interest in partaking in the research. The response rate was $44.4 \%(\mathrm{n}=$ 80). 20 parents who had given the author their contact details were contacted via telephone and provided with questionnaires. The response rate was $100 \%$. Eventually, 100 parents took part in the research, of which mothers were the vast majority. The final research group included in the analysis consisted of 89 mothers of children and adolescents diagnosed with $\mathrm{CF}$ at the age of 0-18.

In 2010, the number of people diagnosed with CF was 1518 (925 were aged 0-20) [23]. Although the average lifespan of the patients with CF was 37 years in the United States [24] and approximately 28 years in Great Britain, the life expectancy of patients with CF in Poland is 18 years [25]. It's worth pointing out that women involved in the research present about $10 \%$ of the population of Polish mothers who take care of children with cystic fibrosis.

\section{Measures}

\section{Socio-demographic data}

Socio-demographic data that were collected included age and gender of the child, family structure, parents' age, parental education and employment, place of residence, declared average monthly income per person in the family, subjec- 
tive evaluation of economic conditions and the average monthly cost of treatment.

\section{The Brief COPE}

The Polish version (Mini-COPE) [22] of the Brief COPE Inventory [17] was used for the assessment of strategies coping with stress. It includes 28 statements which represent 14 groups of stress coping strategies. These statements are grouped into 14 separate subscales of the questionnaire, and each one relates to a particular coping strategy. Each item is evaluated according to a four-item scale (never-sometimes-often-always) ranging from 1 to 4 points. The split-half reliability for the 14 subscales amounts to 0.86 . The calculations were made with the use of SPSS Statistics 22.0 for Windows.

\section{Results}

\section{Sample characteristics}

Sample characteristics is shown in Table 1.

\section{The brief COPE}

Test $t$ for the standalone data was used for the comparison of coping strategies in mothers of CF children and the normative group. The analysis of the average results obtained in the group of mothers proved that the most frequently used coping strategies are the following: active coping, planning and acceptance. Referring to Table 2, positive reframing and seeking for instrumental support were used less frequently by the mothers of children with CF. The classification of other obtained results in accordance with the criterion of the frequency of occurrence provided the following order: seeking for emotional support, religion, venting, self-distraction and self-blame. The following strategies were at a similar level of occurrence: denial, behavioural disengagement and humour. The least frequent approach used by the mothers of children with CF was the usage of psychoactive substances.

The analysis of the data also included the comparison between the average results of the Brief COPE questionnaire and the normative results obtained in the studies on the Polish adult population [23]. Statistically significant differences were verified in 9 out of 14 analysed scales (Table 2). Mothers of children with CF used the following strategies considerably more often than adults in Poland: active coping $(\mathrm{t}=8.99$; $p<0.001)$, planning $(t=8.31 ; p=0.00)$, positive reframing $(\mathrm{t}=2.38 ; \mathrm{p}=0.02)$, acceptance $(\mathrm{t}=4.44 ; \mathrm{p}=0.00)$, religion $(\mathrm{t}=5.74 ; \mathrm{p}=0.00)$,

\section{Table 1. Sample characteristics}

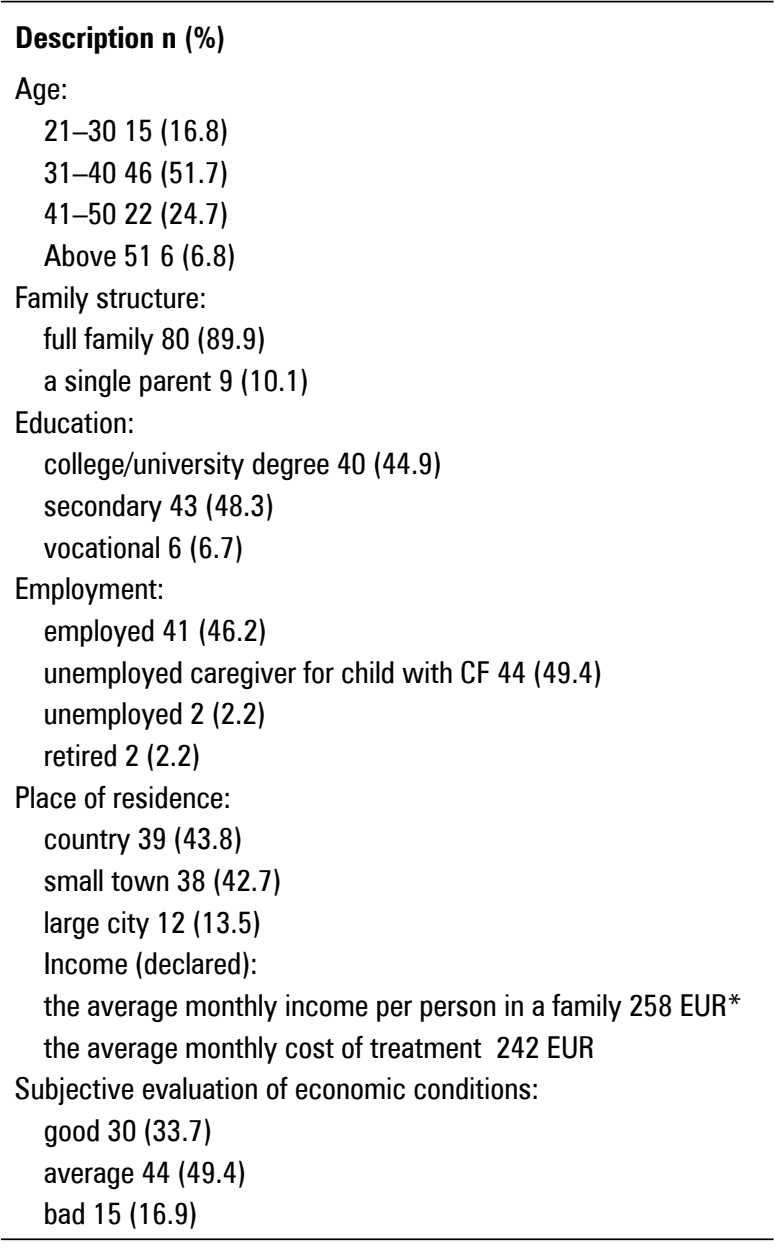

*the average available income in Poland [26]: 297 EUR

seeking for instrumental support $(\mathrm{t}=3.62 ; \mathrm{p}=$ $0.00)$ and venting $(t=5.92 ; p=0.00)$. Sense of humour $(\mathrm{t}=-3.65 ; \mathrm{p}=0.00)$ and taking psychoactive substances $(\mathrm{t}=-2.42 ; \mathrm{p}=0.02)$ turned out to be significantly less frequent.

One of the interesting findings of the study was the fact that mothers of CF children more often choose the strategies focused on the problem rather than on emotions $(t=15.33 ; \mathrm{p}=0.00)$.

\section{Discussion}

Coping with stress in parents of children and adolescents with CF is an important but relatively rarely studied issue. The standards of care published by the European Cystic Fibrosis Society [27] highlight the significance of the coping process in the adjustment of parents of children with CF: ' The diagnosis of CF is traumatic, especially in an otherwise healthy infant. Parents can experience disbelief and dissociation from the diagnosis [...]. Preventative counselling 
Table 2. The comparison of coping strategies in mothers of children and adolescents with CF and a standardised group

\begin{tabular}{|c|c|c|c|c|c|c|}
\hline \multirow[t]{2}{*}{ Coping strategy } & \multicolumn{2}{|c|}{$\begin{array}{l}\text { Mothers of children } \\
\text { and adolescents with CF }\end{array}$} & \multicolumn{2}{|c|}{ Standardised group } & \multirow[t]{2}{*}{$\mathbf{t}$} & \multirow[t]{2}{*}{$\mathbf{p}$} \\
\hline & M & SD & M & SD & & \\
\hline Active coping & 2.42 & 0.58 & 1.87 & 0.79 & 8.99 & 0.00 \\
\hline Planning & 2.39 & 0.57 & 1.89 & 0.79 & 8.31 & 0.00 \\
\hline Positive reframing & 1.86 & 0.75 & 1.67 & 0.77 & 2.38 & 0.02 \\
\hline Acceptance & 2.05 & 0.57 & 1.78 & 0.77 & 4.44 & 0.00 \\
\hline Humour & 0.60 & 0.55 & 0.82 & 0.78 & -3.65 & 0.00 \\
\hline Religion & 1.50 & 1.07 & 0.85 & 0.85 & 5.73 & 0.00 \\
\hline Emotional support & 1.63 & 0.76 & 1.66 & 0.91 & -3.11 & 0.76 \\
\hline Instrumental support & 1.81 & 0.66 & 1.56 & 0.93 & 3.62 & 0.00 \\
\hline Self-distraction & 1.33 & 0.71 & 1.34 & 0.94 & -0.11 & 0.91 \\
\hline Denial & 0.69 & 0.62 & 0.63 & 0.71 & 1.07 & 0.31 \\
\hline Venting & 1.41 & 0.64 & 1.01 & 0.69 & 5.92 & 0.00 \\
\hline Substance use & 0.25 & 0.48 & 0.37 & 0.65 & -2.43 & 0.02 \\
\hline Behavioural disengagement & 0.65 & 0.70 & 0.58 & 0.60 & 0.96 & 0.34 \\
\hline Self-blame & 1.13 & 0.77 & 1.20 & 0.76 & -0.79 & 0.43 \\
\hline
\end{tabular}

CF: cystic fibrosis; M: mean; SD: standard deviation

and emotional support must be offered to assess parents' (i) understanding of information, (ii) reactions to diagnosis and, (iii) coping style, support needs and resources' [28, p. S36].

The diagnosis is usually immediately followed by the medical treatment and the necessity to adhere family life to the specific regime of pharmacotherapy and physiotherapy. Meeting medical requirements necessitates adjusting daily routine to medical treatment. Rehabilitation procedures take up the time devoted to other forms of activity and rest. The parents of children with CF take the effort of reorganising their goals and face a challenge of coping.

The present study aimed at analysing the coping strategies used by the mothers of children and adolescents with CF in comparison with the results of a normative group [22]. The analysis revealed that the obtained results are similar to the outcome of previous studies, which have shown high frequency of adaptive coping behaviours in the population of caregivers of children with cystic fibrosis [13, 15, 18, 20]. Among the coping strategies used by Polish mothers, the most frequent ones are: active coping, acceptance, planning and positive reframing, whereas the strategies based on psychoactive substances usage are very rare. The abovementioned first three positive strategies were also the most frequently used among Australian parents studied by Wong,
Heriot [15]. Seeking emotional support was the dominating coping skill among Australians. Polish mothers, however, more often seek instrumental social support. The similarity of the results to those obtained in Wong's and Heriot's [15] studies also include the least frequently chosen coping strategies such as denial, behavioural disengagement and usage of psychoactive substances.

The comparison of the results obtained from the mothers of children with CF to the normative results of the Polish adults proved that mothers significantly more often use the positive strategies such as active coping, positive reframing, planning, acceptance, turning to religion, and seeking for instrumental support. They also use venting much more often than the normative group of Polish adults. Two strategies significantly less frequently chosen by mothers of children with CF are humour and substance use.

The present study shows that turning to religion is a frequent coping strategy of Polish mothers. The outcome is similar to the one described in another Polish research on parents of children with CF [21], but it is contrary to Wong's and Heriot's study [15]. The issues referring to religious aspects of dealing with stress were presented by Pargament in his works on the subject matter [27]. Grosoehme and Ragsdale et al. [29] also focused on the above-mentioned issue with respect to the psychosocial aspects of CF. 
Polish mothers of children with CF opted twice as often for strategies focusing on the problem rather than strategies concentrating on emotions. Presumably, the requirements concerning the treatment of children with $\mathrm{CF}$ and the related necessity of active involvement in rehabilitation force mothers to adopt task-oriented approach to coping. Although cystic fibrosis remains incurable, the research results show that, probably as a result of determination in fighting the disease, caregivers reveal strength and adaptive coping strategies.

Limitations of the study are as follows:

1. The study did not include a comparative group of mothers who take care of children without cystic fibrosis.

2. The cross-sectional nature of the study did not fully allow for drawing conclusions about the course of coping with stress development in the context of its dynamics and biopsychosocial determinants.

3. The study did not include fathers. According to recent researches, fathers may present a different pattern of coping from mothers.

4. The study sample may have been overrepresented by mothers who are mentally stable and emotionally adjusted (the recruitment procedure was executed during annual conferences and workshops for parents).

\section{Conclusions}

The analysis of the obtained results of the coping strategies chosen by the mothers of children with $\mathrm{CF}$ and their interpretation in the context of the available knowledge on the subject matter allowed for the formulation of the following conclusions:

1. Social support provided to mothers of children with CF should be oriented on strengthening cognitive and spiritual strategies of coping with stress.

2. Mothers of children and adolescents with CF need training to develop the use of positive emotion-focused strategies.

3. Positive image of coping skills may help the mothers themselves and, additionally, create a favourable social perception of families of people with CF.

4. A holistic approach is needed in developing further research on coping strategies used by the mothers of children with CF.

\section{Acknowledgements}

I would like to express my gratitude to the board of the Polish Society Against Cystic Fibrosis and all mothers for being involved in the research and for their helpful support.

This research did not receive any specific grant from funding agencies in the public, commercial, or not-for-profit sectors.

The results of the study were presented at the $38^{\text {th }}$ European Cystic Fibrosis Conference (1013.06.2015, Brussels, Belgium). The abstract was published in Journal of Cystic Fibrosis, Vol.14, Suppl. 1, p. 5.

The presentation was awarded as 'Best Poster Award Nursing/Psychosocial Issues/Quality Improvement'.

\section{References:}

1. Ronan NJ, Elborn JS, Plant BJ. Current and emerging comorbidities in cystic fibrosis. Presse Med. 2017; 46(6 Pt 2): e125e138, doi: 10.1016/j.lpm.2017.05.011, indexed in Pubmed: 28554721.

2. Glasscoe C, Lancaster GA, Smyth RL, et al. Parental depression following the early diagnosis of cystic fibrosis: a matched, prospective study. J Pediatr. 2007; 150(2): 185-191, doi: 10.1016/j. jpeds.2006.11.022, indexed in Pubmed: 17236898.

3. Driscoll KA, Johnson SB, Barker D, et al. Risk factors associated with depressive symptoms in caregivers of children with type 1 diabetes or cystic fibrosis. J Pediatr Psychol. 2010; 35(8): 814-822, doi: 10.1093/jpepsy/jsp138, indexed in Pubmed: 20097908.

4. Quittner AL, Goldbeck L, Abbott J, et al. Prevalence of depression and anxiety in patients with cystic fibrosis and parent caregivers: results of The International Depression Epidemiological Study across nine countries. Thorax. 2014; 69(12): 1090-1097, doi: 10.1136/thoraxjnl-2014-205983, indexed in Pubmed: 25246663

5. Harrop M. Psychosocial impact of cystic fibrosis in adolescence. Paediatr Nurs. 2007; 19(10): 41-45, doi: 10.7748/ paed2007.12.19.10.41.c6432, indexed in Pubmed: 18196861.

6. Thompson RJ, Gustafson KE, Hamlett KW, et al. Stress, coping, and family functioning in the psychological adjustment of mothers of children and adolescents with cystic fibrosis. J Pediatr Psychol. 1992; 17(5): 573-585, indexed in Pubmed: 1432482.

7. Blair C, Cull A, Freeman CP. Psychosocial functioning of young adults with cystic fibrosis and their families. Thorax. 1994; 49(8): 798-802, indexed in Pubmed: 8091327.

8. Foster CL, Bryon M, Eiser C. Correlates of well-being in mothers of children and adolescents with cystic fibrosis. Child Care Health Dev. 1998; 24(1): 41-56, indexed in Pubmed: 9468779.

9. Lazarus RS, Folkman S. Stress, appraisal, and coping. Springer New York 1984

10. Hobfoll SE. Conservation of resources. A new attempt at conceptualizing stress. Am Psychol. 1989; 44(3): 513-524, indexed in Pubmed: 2648906

11. Antonovsky A. Rozwikłanie tajemnicy zdrowia. Fundacja IPN, Warszawa 1995

12. Lazarus RS. Radzenie sobie ze stresem wywołanym chorobą. In: Kaplun A. ed. Promocja zdrowia w chorobach przewlekłych. Odkrywanie nowej jakości zdrowia. Instytut Medycyny Pracy, Łódź 1997: 3-15.

13. Havermans T, Tack J, Vertommen A, et al. Breaking bad news, the diagnosis of cystic fibrosis in childhood. J Cyst Fibros. 2015; 14(4): 540-546, doi: 10.1016/j.jcf.2014.12.005, indexed in Pubmed: 25563520.

14. Staab D, Wenninger K, Gebert N, et al. Quality of life in patients with cystic fibrosis and their parents: what is important besides disease severity? Thorax. 1998; 53(9): 727-731, indexed in Pubmed: 10319053.

15. Wong MG, Heriot SA. Parents of children with cystic fibrosis: how they hope, cope and despair. Child Care Health Dev. 
2008; 34(3): 344-354, doi: 10.1111/j.1365-2214.2007.00804.x, indexed in Pubmed: 18294259.

16. Sheehan J, Hiscock H, Massie J, et al. Caregiver coping, mental health and child problem behaviours in cystic fibrosis: a crosssectional study. Int J Behav Med. 2014; 21(2): 211-220, doi: 10.1007/s12529-013-9289-y, indexed in Pubmed: 23325547.

17. Carver CS. You want to measure coping but your protocol's too long: consider the brief COPE. Int J Behav Med. 1997; 4(1): 92-100, doi: 10.1207/s15327558ijbm0401_6, indexed in Pubmed: 16250744 .

18. Hodkova P, Abbott J, Mala I, et al. Coping with cystic fibrosis - CF adults and parents of a child with CF in Czech Republic. Journal of Cystic Fibrosis. 2008; 7: S110, doi: 10.1016/s15691993(08)60422-1.

19. Thompson RJ, Gustafson KE, Hamlett KW, et al. Psychological adjustment of children with cystic fibrosis: the role of child cognitive processes and maternal adjustment. J Pediatr Psychol. 1992; 17(6): 741-755, indexed in Pubmed: 1484336.

20. Hodgkinson R, Lester H. Stresses and coping strategies of mothers living with a child with cystic fibrosis: implications for nursing professionals. J Adv Nurs. 2002; 39(4): 377-383, indexed in Pubmed: 12139650.

21. Kornas-Biela D. Coping strategies in CF families. Acta Univ Carol Med (Praha). 1990; 36(1-4): 233-234, indexed in Pubmed: 2130707.

22. Juczyński Z, Ogińska-Bulik N. Narzędzia pomiaru stresu i radzenia sobie ze stresem, Pracownia Testów Psychologicznych: Warszawa.
23. Kopciuch D, Zaprutko T, Paczkowska A, et al. Costs of treatment of adult patients with cystic fibrosis in Poland and internationally. Public Health. 2017; 148: 49-55, doi: 10.1016/j. puhe.2017.03.003, indexed in Pubmed: 28404533.

24. Ernst MM, Johnson MC, Stark LJ. Developmental and psychosocial issues in cystic fibrosis. Child Adolesc Psychiatr Clin N Am. 2010; 19(2): 263-83, viii, doi: 10.1016/j.chc.2010.01.004, indexed in Pubmed: 20478499.

25. Mazurek H. Postępy w mukowiscydozie. Klin Pediatr. 2009; 17(1): 89-92.

26. Sytuacja gospodarstw domowych w 2014 r. w świetle wyników badań budżetów gospodarstw domowych, GUS. gov pl/obszary-tematyczne/warunki-zycia/dochody-wydatki-i-warunki-zycia-ludnosci/sytuacja-gospodarstw-domowych-w2014-r-w-swietle-wynikow-badan-budzetow-gospodarstw-domowych,3,14 html.

27. Pargament KI. The psychology of religion and coping. Theory, Research, Practice. The Guilford Press, New York 1997: London.

28. Smyth AR, Bell SC, Bojcin S, et al. European Cystic Fibrosis Society. European cystic fbrosis society standards of care: best practice guidelines. J Cyst Fibros. 2014; 13 Suppl 1: S23-S42, doi: 10.1016/j.jcf.2014.03.010, indexed in Pubmed: 24856775.

29. Grossoehme DH, Ragsdale JR, Snow A, et al. We were chosen as a family: parents' evolving use of religion when their child has cystic fibrosis. J Relig Health. 2012; 51(4): 1347-1358, doi: 10.1007/s10943-011-9477-5, indexed in Pubmed: 21409481. 